\title{
AVALIAÇÃO DA ESTABILIDADE OXIDATIVA DE BIODIESEL E SUAS MISTURAS COM DIESEL ATRAVÉS DA CALORIMETRIA EXPLORATÓRIA DIFERENCIAL PRESSURIZADA (PDSC)
}

\author{
Bruno Dias de Castro Ferreira dos Santos ${ }^{1}$, Jussara Lopes de Miranda ${ }^{2}$, Roberta \\ Miranda Teixeira $^{1}$ \\ ${ }^{1}$ /piranga Produtos de Petróleo S.A., ${ }^{2}$ Universidade Federal do Rio de Janeiro \\ E-mails: brunods@ipiranga.com.br; robertamt@ipiranga.com.br; jussara@iq.ufri.br
}

\section{RESUMO}

O teor de biodiesel no diesel tende a aumentar cada vez mais no Brasil, tendo como objetivos diminuir o custo com a importação do diesel e aumentar a parcela de uso de energia renovável. Entretanto, a baixa estabilidade oxidativa do biodiesel é uma das barreiras para sua ampla aceitação comercial. Portanto, é de fundamental importância que se desenvolvam testes de oxidação acelerada capazes de avaliar essa propriedade crítica, tanto para o biodiesel puro, quanto para suas misturas com 0 diesel.

Sendo assim, o objetivo deste trabalho é avaliar a estabilidade oxidativa do biodiesel e suas misturas com diesel através da Calorimetria Exploratória Diferencial Pressurizada (PDSC), técnica na qual se mede a variação do fluxo de calor no decorrer da reação.

Foram avaliadas amostras de biodiesel e diesel (S10 e S500), além de misturas B7 e B20, através de curvas isotérmicas e não-isotérmicas no PDSC. Os resultados foram comparados com o Rancimat (EN 15751 e EN 14112), metodologia atualmente reconhecida pela Agência Nacional de Petróleo, Gás natural e Biocombustíveis (ANP).

Foram obtidos resultados coerentes com o Rancimat, sendo identificados os fatores que influenciam significativamente na estabilidade oxidativa das misturas, e o impacto causado pela adição do biodiesel.

Palavras-chave: Biodiesel, Diesel, Estabilidade Oxidativa, Rancimat, PDSC.

\section{INTRODUÇÃO}

Nas últimas décadas, tem-se buscado assiduamente o desenvolvimento de energia sustentável. Esse crescimento é acompanhado por incentivos de diversos governos ao redor do mundo para a melhoria da produção e o consumo de energias renováveis.

Nesse contexto, o biodiesel foi introduzido na matriz energética brasileira em Janeiro de 2005, com o lançamento do Programa Nacional de Biodiesel, visando a produção 
de biodiesel a partir de diferentes matérias-primas, favorecendo a agricultura familiar, tendo como foco a inclusão social e o desenvolvimento regional. Atualmente, ele é comercializado como uma mistura com diesel na proporção de 8\% (B8); e esse teor tende a aumentar cada vez mais [1].

Um dos principais problemas do biodiesel é a dificuldade de assegurar sua qualidade ao longo de toda a cadeia produtiva, principalmente em relação a sua baixa estabilidade oxidativa comparada com o diesel, o que afeta consideravelmente o seu armazenamento.

O método utilizado de acordo com as Resolução ANP no 45 de 25/08/2014 e n³0 de 23/06/2016 [2,3] para avaliar a estabilidade oxidativa do biodiesel e suas misturas com o diesel é o método do Rancimat, na qual a amostra é aquecida a $110^{\circ} \mathrm{C}$ sob uma vazão de ar definida. O parâmetro medido é a condutividade de uma solução de água deionizada. Conforme o biodiesel é oxidado são formados peróxidos, que serão degradados em ácidos carboxílicos leves, principalmente, ácido fórmico e acético, que irão ser transportados para a solução de água, fazendo com que sua condutividade aumente consideravelmente.

Devido à grande importância dessa propriedade, vem sendo realizados diversos estudos a fim de aprimorar a sua avaliação através de outras técnicas. A principal delas é a Calorimetria Exploratória Diferencial Pressurizada (PDSC), onde é medido a variação do fluxo de calor no decorrer da reação, seja ela isotérmica (temperatura constante) onde-se determina o tempo de indução oxidativa (OIT) ou não-isoterma (rampa de aquecimento), se determinando a temperatura de oxidação (OT). Podendo ainda serem feitas curvas dinâmicas (com fluxo de gás) ou estáticas (sem fluxo). No caso da oxidação é verificado uma variação positiva no fluxo de calor, já que se trata de um evento exotérmico.

Diferentemente do Rancimat, o PDSC mede a liberação de energia da reação de oxidação ao invés de qualquer produto químico específico de oxidação, uma vez que a análise é realizada diretamente na amostra [4]. Devido a isso, acredita-se que os dois métodos não reflitam o mesmo estágio do processo de oxidação. No PDSC observa-se um pico exotérmico, relativo ao início da etapa de propagação. Já no Rancimat, se observa o aumento da condutividade causada pela formação de produtos voláteis (oxidação secundária), o que estaria relacionado ao processo de terminação, conforme mostra a figura 1 [5].

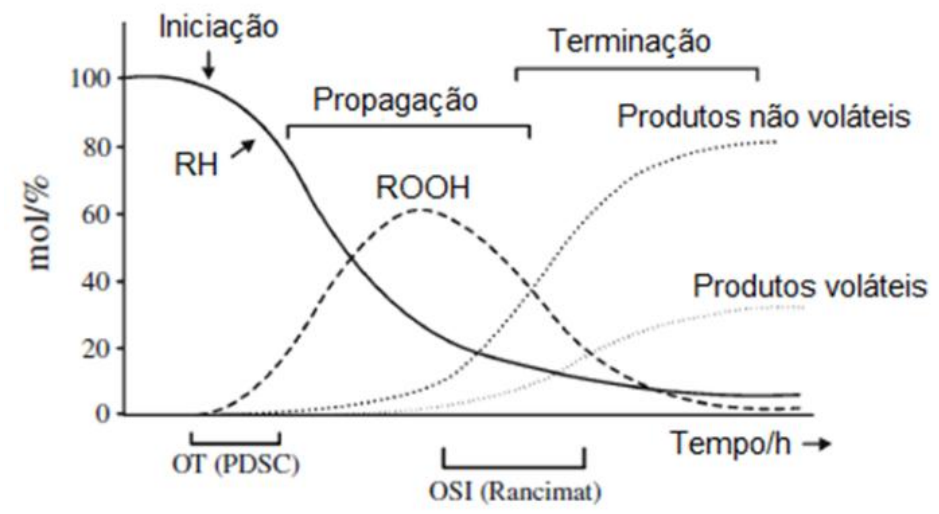

Figura 1 Oxidação de ácidos graxos insaturados em função do tempo. 


\section{MATERIAIS E MÉTODOS}

\subsection{Materiais}

\subsubsection{Biodiesel}

O biodiesel comercial utilizado neste trabalho foi produzido por rota metílica utilizando como matéria-prima óleo de soja (63\%) e sebo bovino (37\%), sem adição de antioxidante. Ele foi caracterizado pelo fornecedor de acordo com a resolução ANP no14 de 11/5/2012 [6]. Os resultados obtidos estão na tabela 1.

Tabela 1 - Características físico-químicas do biodiesel utilizado no trabalho

\begin{tabular}{|c|c|c|c|c|}
\hline Característica & Unidade & Resultado & Especificação & Método \\
\hline Aspecto & - & $\begin{array}{l}\text { Límpido e isento } \\
\text { de impurezas }\end{array}$ & $\begin{array}{l}\text { Límpido e } \\
\text { isento de } \\
\text { impurezas }\end{array}$ & Visual \\
\hline $\begin{array}{c}\text { Massa específica a } \\
20^{\circ} \mathrm{C}\end{array}$ & $\mathrm{kg} / \mathrm{m}^{3}$ & 876,3 & 850 a 900 & NBR 7148 \\
\hline $\begin{array}{c}\text { Viscosidade } \\
\text { Cinemática a } 40^{\circ} \mathrm{C}\end{array}$ & $\mathrm{mm}^{2} / \mathrm{s}$ & 4,68 & 3,0 a 6,0 & ASTM D445 \\
\hline Teor de água & $\mathrm{mg} / \mathrm{kg}$ & 167,5 & 200, máx & ASTM D6304 \\
\hline Contaminação Total & $\mathrm{mg} / \mathrm{kg}$ & 16,4 & 24, máx & EN 12662 \\
\hline Ponto de fulgor & $\stackrel{\circ}{ } \mathrm{C}$ & 121,4 & 100,0, mín & NBR 14598 \\
\hline Teor de éster & $\%$ massa & 97,4 & 96,5, mín & EN 14103 \\
\hline Resíduo de carbono & $\%$ massa & 0,033 & 0,050, máx & ASTM D4530 \\
\hline Cinzas sulfatadas & $\%$ massa & $<0,005$ & 0,020, máx & NBR 6294 \\
\hline Enxofre total & $\mathrm{mg} / \mathrm{kg}$ & 2,37 & 10, máx & ASTM D5453 \\
\hline Sódio + Potássio & $\mathrm{mg} / \mathrm{kg}$ & $<1,00$ & 5, máx & NBR 15556 \\
\hline Cálcio + Magnésio & $\mathrm{mg} / \mathrm{kg}$ & $<1,00$ & 5, máx & NBR 15556 \\
\hline Fósforo & $\mathrm{mg} / \mathrm{kg}$ & $<1,00$ & 10, máx & ASTM D4951 \\
\hline $\begin{array}{l}\text { Corrosividade ao } \\
\text { cobre }\end{array}$ & - & $1 \mathrm{~A}$ & 1, máx & NBR 14359 \\
\hline Número Cetano & - & - & Anotar & ADTM D6890 \\
\hline $\begin{array}{l}\text { Ponto de } \\
\text { entupimento de filtro } \\
\text { a frio }\end{array}$ & $\stackrel{\circ}{ } \mathrm{C}$ & 7 & Tabela 2 & ASTM D6371 \\
\hline Índice de acidez & $\mathrm{mg} \mathrm{KOH} / \mathrm{g}$ & 0,19 & 0,50, máx & NBR 14448 \\
\hline Glicerol livre & $\%$ massa & 0,01 & 0,02, máx & ASTM D6584 \\
\hline Glicerol total & $\%$ massa & 0,05 & 0,25, máx & ASTM D6584 \\
\hline Monoacilglicerol & $\%$ massa & 0,09 & 0,80, máx & ASTM D6584 \\
\hline Diacilglicerol & $\%$ massa & 0,04 & 0,20, máx & ASTM D6584 \\
\hline
\end{tabular}




\begin{tabular}{ccccc}
\hline Triacilglicerol & $\%$ massa & 0,06 & 0,20, máx & ASTM D6584 \\
\hline Metanol, máx. & $\%$ massa & $<0,05$ & 0,20 , máx & EN 14110 \\
\hline Índice de lodo & $\mathrm{g} / 100 \mathrm{~g}$ & 95,5 & Anotar & EN 14111 \\
\hline $\begin{array}{c}\text { Estabilidade à } \\
\text { oxidação a } 110^{\circ} \mathrm{C}\end{array}$ & $\mathrm{h}$ & 9,9 & 6, mín & EN 14112 \\
\hline
\end{tabular}

Dados reportados do certificado de análise nº BBD 0001/2014.

Tabela 2. Especificação para o Ponto de entupimento de filtro a frio.

\begin{tabular}{ccccccccccccc}
\hline Unidades de & \multicolumn{10}{c}{ Limite máximo, o- } \\
\cline { 2 - 15 } federação & Jan & Fev & Mar & Mai & Abr & Jun & Jul & Ago & Set & Out & Nov & Dez \\
\hline SP - MG - MS & 14 & 14 & 14 & 12 & 8 & 8 & 8 & 8 & 8 & 12 & 14 & 14 \\
\hline $\begin{array}{c}\text { GO/DF - MT - } \\
\text { ES - RJ }\end{array}$ & 14 & 14 & 14 & 14 & 10 & 10 & 10 & 10 & 10 & 14 & 14 & 14 \\
\hline PR - SC - RS & 14 & 14 & 14 & 10 & 5 & 5 & 5 & 5 & 5 & 10 & 14 & 14 \\
\hline
\end{tabular}

Fonte: Resolução no14/2012 - ANP.

A amostras de biodiesel foi coletada da base de Duque de Caxias da Ipiranga Produtos de Petróleo, em 2013. E, portanto, foi especificada de acordo com a resolução vigente da época [6], e não, com a resolução vigente atualmente [2].

\subsubsection{Diesel S10 e Diesel S500}

Os óleos diesel A S10 e S500 comerciais utilizados neste trabalho foram caracterizados pelo fabricante. O produto foi especificado conforme os parâmetros listados na Resolução ANP $\mathrm{n} \div 50$ de 23/12/2013 [7]. Os resultados obtidos estão na tabela 3.

Tabela 3 Características físico-químicas do diesel S10 e S500 utilizados no trabalho.

\begin{tabular}{|c|c|c|c|c|c|c|c|}
\hline \multirow{2}{*}{\multicolumn{2}{|c|}{ Característica }} & \multirow{2}{*}{ Unidade } & \multicolumn{2}{|c|}{ Resultado } & \multicolumn{2}{|c|}{ Especificação } & \multirow{2}{*}{ Método } \\
\hline & & & $\mathrm{S} 10$ & S500 & $\mathrm{S} 10$ & S500 & \\
\hline \multicolumn{2}{|c|}{ Aspecto } & - & \multicolumn{2}{|c|}{$\begin{array}{l}\text { Límpido e isento de } \\
\text { impurezas }\end{array}$} & \multicolumn{2}{|c|}{$\begin{array}{l}\text { Límpido e isento } \\
\text { de impurezas }\end{array}$} & $\begin{array}{l}\text { ASTM } \\
\text { D4176 }\end{array}$ \\
\hline \multicolumn{2}{|c|}{ Cor } & - & \multicolumn{2}{|c|}{ INAM (1) } & \multicolumn{2}{|c|}{ INAM } & Visual \\
\hline \multicolumn{2}{|c|}{ Cor ASTM } & - & \multicolumn{2}{|c|}{ L1.0 } & \multicolumn{2}{|c|}{$\mathrm{L} 1,0$} & $\begin{array}{l}\text { ASTM } \\
\text { D1500 }\end{array}$ \\
\hline \multirow{4}{*}{ Destilação } & $\begin{array}{c}10 \% \\
\text { recuperados }\end{array}$ & \multirow{4}{*}{$\stackrel{\circ}{ } \mathrm{C}$} & 213,9 & 186,0 & $\begin{array}{l}180,0, \\
\text { mín }\end{array}$ & Anotar & \multirow{4}{*}{$\begin{array}{l}\text { ASTM } \\
\text { D86 }\end{array}$} \\
\hline & $\begin{array}{l}50 \% \\
\text { recuperados }\end{array}$ & & 278,7 & 264,6 & $\begin{array}{c}245,0 \mathrm{a} \\
295,0\end{array}$ & $\begin{array}{c}245,0 \mathrm{a} \\
310,0\end{array}$ & \\
\hline & $\begin{array}{l}85 \% \\
\text { recuperados }\end{array}$ & & - & 340,4 & - & Anotar & \\
\hline & $\begin{array}{c}95 \% \\
\text { recuperados }\end{array}$ & & 367,0 & 357,9 & $\begin{array}{l}\text { 370,0, } \\
\text { máx }\end{array}$ & $\begin{array}{l}\text { 500, } \\
\text { máx }\end{array}$ & \\
\hline \multicolumn{2}{|c|}{$\begin{array}{l}\text { Ponto de entupimento de } \\
\text { filtro a frio (CFPP) }\end{array}$} & $\stackrel{\circ}{ } \mathrm{C}$ & -2 & -4 & \multicolumn{2}{|c|}{ Tabela 4} & $\begin{array}{l}\text { ASTM } \\
\text { D6371 }\end{array}$ \\
\hline
\end{tabular}




\begin{tabular}{|c|c|c|c|c|c|c|}
\hline Massa específica a $20^{\circ} \mathrm{C}$ & $\mathrm{kg} / \mathrm{m} 3$ & 827,6 & 846,8 & $\begin{array}{c}815,0 \mathrm{a} \\
850,0\end{array}$ & $\begin{array}{c}815,0 a \\
865,0\end{array}$ & $\begin{array}{l}\text { ASTM } \\
\text { D4052 }\end{array}$ \\
\hline $\begin{array}{l}\text { Viscosidade cinemática a } \\
\qquad 40^{\circ} \mathrm{C}\end{array}$ & $\mathrm{mm}^{2} / \mathrm{s}$ & 3,097 & 2,809 & $\begin{array}{c}2,0 \mathrm{a} \\
4,5\end{array}$ & $\begin{array}{c}2,0 \mathrm{a} \\
5,0\end{array}$ & $\begin{array}{c}\text { ASTM } \\
\text { D445 }\end{array}$ \\
\hline Corrosividade ao cobre & - & \multicolumn{2}{|c|}{1} & \multicolumn{2}{|c|}{ 1, máx } & $\begin{array}{c}\text { ASTM } \\
\text { D130 }\end{array}$ \\
\hline Extabilidade oxidativa & $\mathrm{mg} / 100 \mathrm{ml}$ & 0,2 & - & 2,5, máx & - & $\begin{array}{l}\text { ASTM } \\
\text { D2274 }\end{array}$ \\
\hline Índice de neutralização & $\mathrm{mg} \mathrm{KOH} / \mathrm{g}$ & 0,00 & - & Anotar & & $\begin{array}{l}\text { ASTM } \\
\text { D974 }\end{array}$ \\
\hline Cinzas & $\%$ massa & \multicolumn{2}{|c|}{$<0,0010$} & \multicolumn{2}{|c|}{ 0,010, máx } & $\begin{array}{c}\text { ASTM } \\
\text { D482 }\end{array}$ \\
\hline $\begin{array}{l}\text { Resíduo de carbono } \\
\text { Ramsbottom nos } 10 \% \text { finais } \\
\text { da destilação }\end{array}$ & \%massa & 0,08 & 0,11 & \multicolumn{2}{|c|}{0,25 , máx } & $\begin{array}{l}\text { ASTM } \\
\text { D524 }\end{array}$ \\
\hline Número de cetano & - & 58,1 & - & 48, mín & - & $\begin{array}{c}\text { ASTM } \\
\text { D613 }\end{array}$ \\
\hline Índice de cetano calculado & - & - & 45 & - & 45, mín & $\begin{array}{l}\text { ASTM } \\
\text { D4737 }\end{array}$ \\
\hline Contaminação total & $\mathrm{mg} / \mathrm{kg}$ & 1,2 & - & 24, máx & - & $\begin{array}{c}\text { EN } \\
12662\end{array}$ \\
\hline Água e sedimentos & $\%$ volume & \multicolumn{2}{|c|}{$<0,050$} & \multicolumn{2}{|c|}{ 0,05, máx } & $\begin{array}{l}\text { ASTM } \\
\text { D2709 }\end{array}$ \\
\hline Teor de água & $\mathrm{mg} / \mathrm{kg}$ & 56 & - & $\begin{array}{l}\text { 200, } \\
\text { máx }\end{array}$ & - & $\begin{array}{l}\text { ASTM } \\
\text { D6304 }\end{array}$ \\
\hline $\begin{array}{l}\text { Hidrocarbonetos policíclicos } \\
\text { aromáticos }\end{array}$ & $\%$ massa & 2,65 & - & 11, máx & - & $\begin{array}{l}\text { ASTM } \\
\text { D5186 }\end{array}$ \\
\hline Ponto de fulgor & $\stackrel{\circ}{ } \mathrm{C}$ & 60,0 & 44 & \multicolumn{2}{|c|}{ 38,0, mín } & $\begin{array}{c}\text { ASTM } \\
\text { D93 }\end{array}$ \\
\hline Enxofre total & $\mathrm{mg} / \mathrm{kg}$ & 5,2 & 403 & $\begin{array}{l}\text { 10,0, } \\
\text { máx }\end{array}$ & $\begin{array}{l}500, \\
\text { máx }\end{array}$ & $\begin{array}{l}\text { ASTM } \\
\text { D5453 / } \\
\text { D4052 }\end{array}$ \\
\hline Condutividade elétrica & $\mathrm{pS} / \mathrm{m}$ & 60 & 103 & \multicolumn{2}{|c|}{ 25, mín } & $\begin{array}{l}\text { ASTM } \\
\text { D2624 }\end{array}$ \\
\hline
\end{tabular}

Dados reportados do certificado de análise no 1658-2014 e 1668-2014. Notas: (1) Incolor a amarelada (no caso do diesel S500 foi realizado o ensaio antes da adição do corante vermelho).

Tabela 4. Especificação para o Ponto de entupimento de filtro a frio.

\begin{tabular}{ccccccccccccc}
\hline Unidades de & \multicolumn{10}{c}{ Limite máximo, ${ }^{\circ} \mathbf{c}$} \\
\cline { 2 - 16 } federaça & Jan & Fev & Mar & Mai & Abr & Jun & Jul & Ago & Set & Out & Nov & Dez \\
\hline SP - MG - MS & 14 & 14 & 14 & 12 & 8 & 8 & 8 & 8 & 8 & 12 & 14 & 14 \\
\hline $\begin{array}{c}\text { GO/DF - MT - } \\
\text { ES - RJ }\end{array}$ & 14 & 14 & 14 & 14 & 10 & 10 & 10 & 10 & 10 & 14 & 14 & 14 \\
\hline PR - SC - RS & 14 & 14 & 14 & 10 & 5 & 5 & 5 & 5 & 5 & 10 & 14 & 14 \\
\hline
\end{tabular}

Fonte: Resolução nํ50/2013 - ANP.

\subsubsection{Amostras avaliadas}

Foram preparadas misturas de óleo diesel A S10 e S500 com o biodiesel nas proporções de 7 e $20 \%$ (v/v), denominadas respectivamente $\mathrm{B} 7$ e $\mathrm{B} 20$. O diesel puro foi denominado $\mathrm{B} 0$ e o biodiesel puro, B100. 


\subsection{Métodos}

\subsubsection{Rancimat}

Foi utilizado o equipamento Rancimat, modelo 873, da Metrohm (figura 2 e 3) para avaliar a estabilidade oxidativa do B100 e das misturas B7 e B20, de acordo com as normas descritas abaixo, sendo realizadas análises em triplicata.

A estabilidade oxidativa é determinada pelo período de indução, ou índice de estabilidade oxidativa (OSI), que é o intervalo entre o início da análise e quando a condutividade da solução aumenta bruscamente.

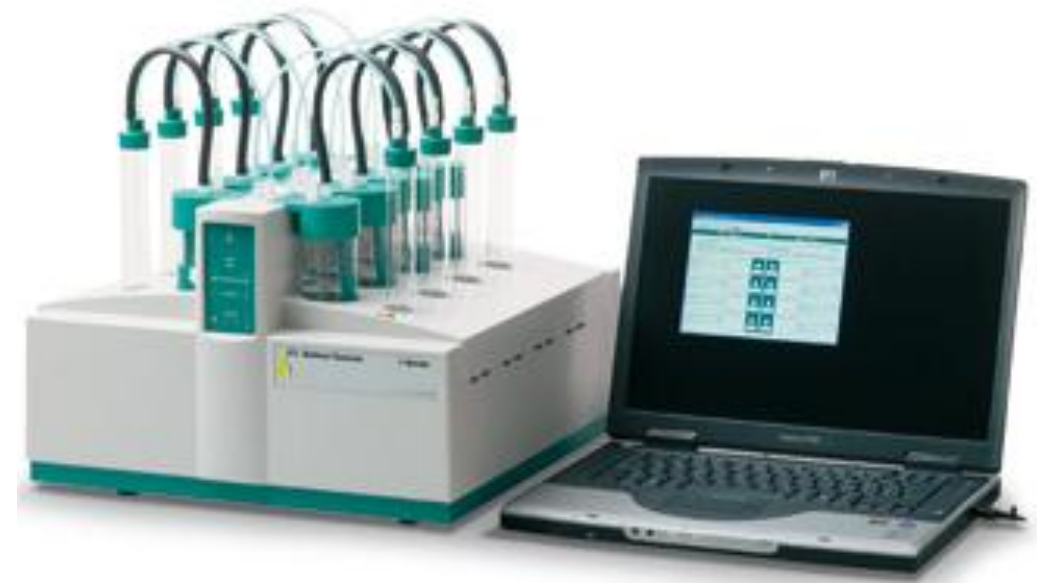

Figura 2. Equipamento Rancimat. Fonte: Metrohm. Disponível em $<$ http://biofuels. metrohm.com/stability/ principle.html> Acesso em 04 jun.2014.

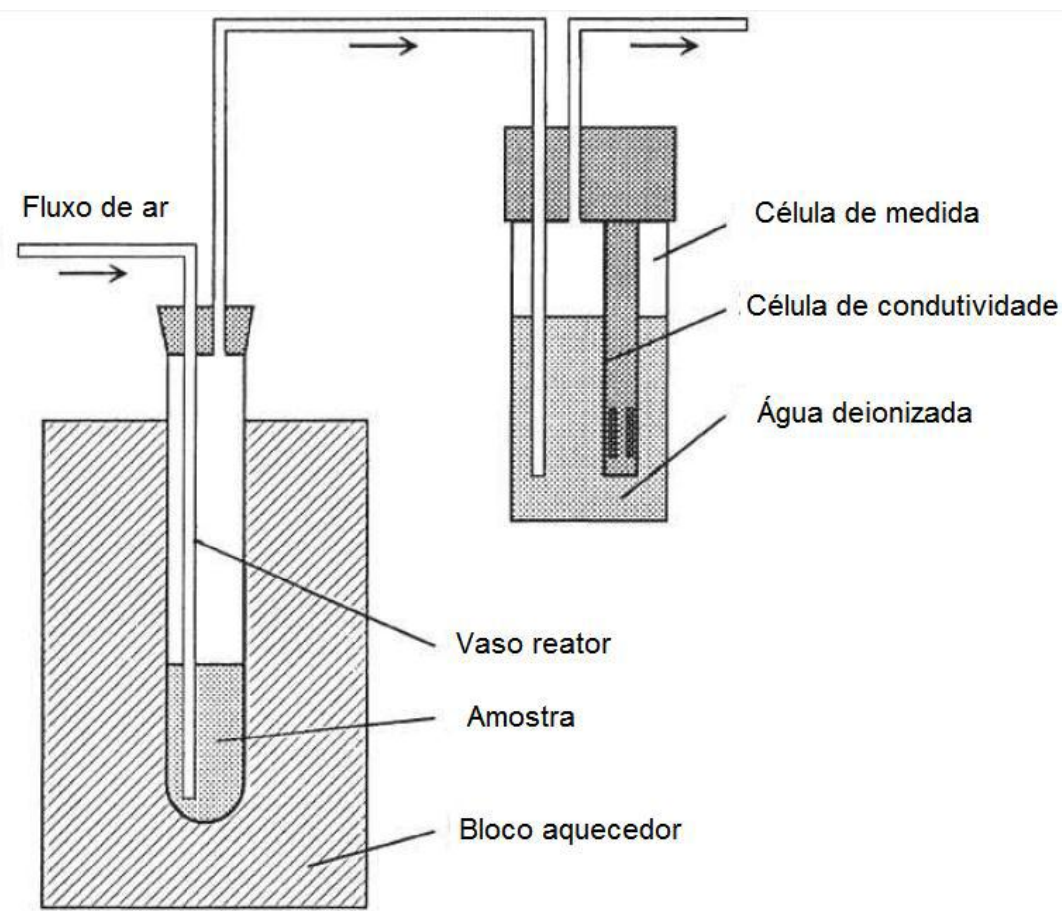

Figura 3. Esquema do teste Rancimat. Fonte: EN 14112, 2003. 
- $\quad$ EN 14112 (B100) [8]:

Utilizou-se uma massa de $(3,00+0,01) \mathrm{g}$ de amostra a uma temperatura de $110^{\circ} \mathrm{C}$ com uma vazão de ar de $10 \mathrm{l} / \mathrm{h}$. Na célula de medida foram adicionados $50 \mathrm{ml}$ de água deionizada com condutividade menor que 5 $\mu \mathrm{S} / \mathrm{cm}$.

- $\quad$ EN 15751 (B7 e B20) [9]:

Utilizou-se uma massa de $(7,5+0,1) \mathrm{g}$ de amostra a uma temperatura de $110^{\circ} \mathrm{C}$ com uma vazão de ar de 10l/h. No célula de medida foram adicionados $60 \mathrm{ml}$ de água deionizada com condutividade menor que 5 $\mu \mathrm{S} / \mathrm{cm}$. Essa norma exige um vaso de reação maior, tendo que ficar $13,0 \mathrm{~cm}$ ou mais acima do equipamento.

\subsubsection{PDSC}

As análises por PDSC foram realizadas no equipamento DSC da TA Instruments, modelo Q2000 acoplado a uma célula de pressão (figura 4) em cadinhos de alumínio abertos (figura 5). A calibração da célula foi feita medindo o ponto de fusão do Indio a uma taxa de $10^{\circ} \mathrm{C} / \mathrm{min}$. Foram realizados dois métodos distintos, como descritos abaixo. Em ambos utilizou-se amostras da ordem de $3 \mathrm{mg}$.

- Isotérmico

A célula foi pressurizada a 290 psi, mantendo a temperatura a $110^{\circ} \mathrm{C}$, utilizando oxigênio como oxidante, sem fluxo. Esse método de análise foi utilizado somente para a amostra de B100.

- Não-isotérmico

Foi utilizado esse método para todas as amostras (B0, B7, B20 e B100). As análises foram feitas com uma rampa de aquecimento de $10^{\circ} \mathrm{C} / \mathrm{min}$ desde a temperatura ambiente até $300^{\circ} \mathrm{C}$. Utilizou-se a mesma pressão de 290 psi e o mesmo oxidante sem fluxo. Foram realizadas análises em triplicata. 


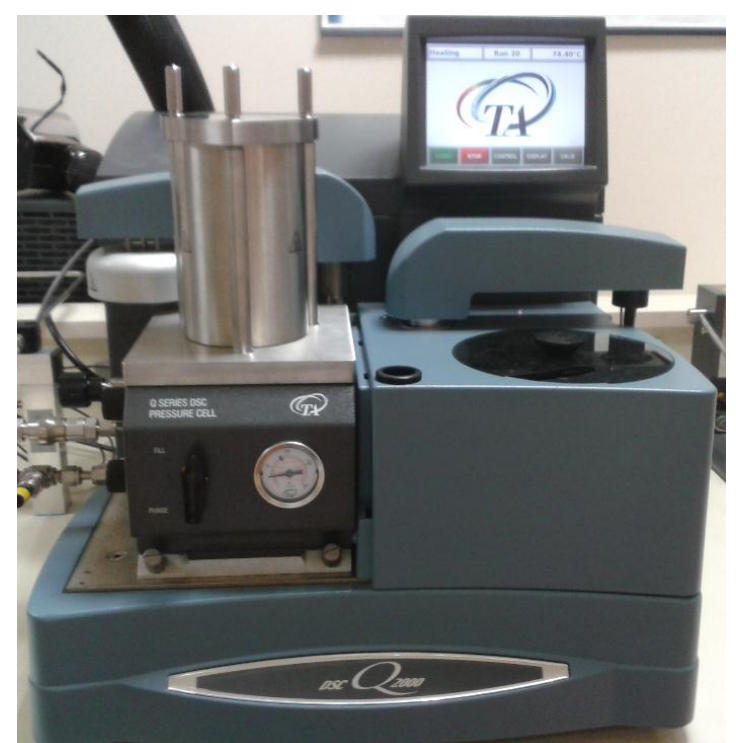

Figura 4. Fotografia do equipamento DSC Q2000.

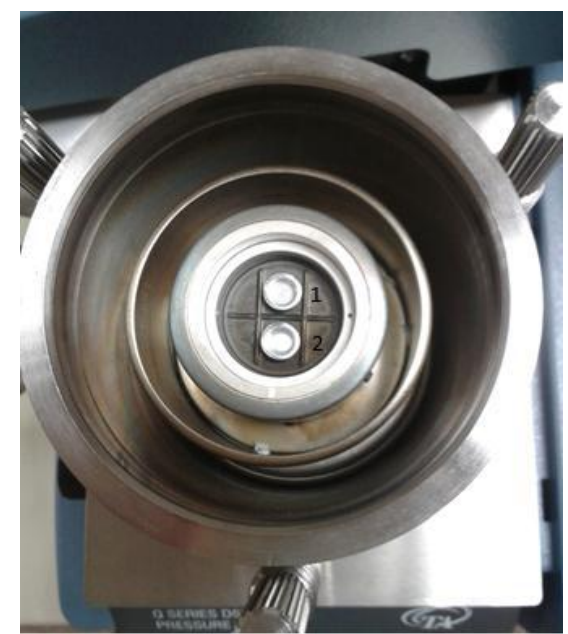

Figura 5. Vista superior do interior da célula de pressão. 1 - panela de referência (vazia); 2 - panela de amostra.

\section{RESULTADOS E DISCUSSÃO}

\subsection{Biodiesel puro (B100)}

Na figura 6 está apresentada a curva isotérmica de PDSC a uma temperatura de $110^{\circ} \mathrm{C}$, mesma temperatura utilizada no método do Rancimat. O valor obtido de OIT para o B100 foi de 16,96 minutos, o que representa o tempo no qual a amostra resiste à oxidação nas condições específicas do teste.

Observa-se um pico referente a oxidação da amostra, marcado por um aumento do fluxo de calor. O valor de OIT é obtido pela interseção da tangente traçada a partir da linha de base e da linha ascendente no pico exotérmico de oxidação. 
Os valores reportados na literatura variam devido as diferenças entre as amostras de biodiesel (matérias-primas utilizadas em sua produção), além das condições utilizadas na análise de PDSC (temperatura, pressão, oxidante e fluxo).

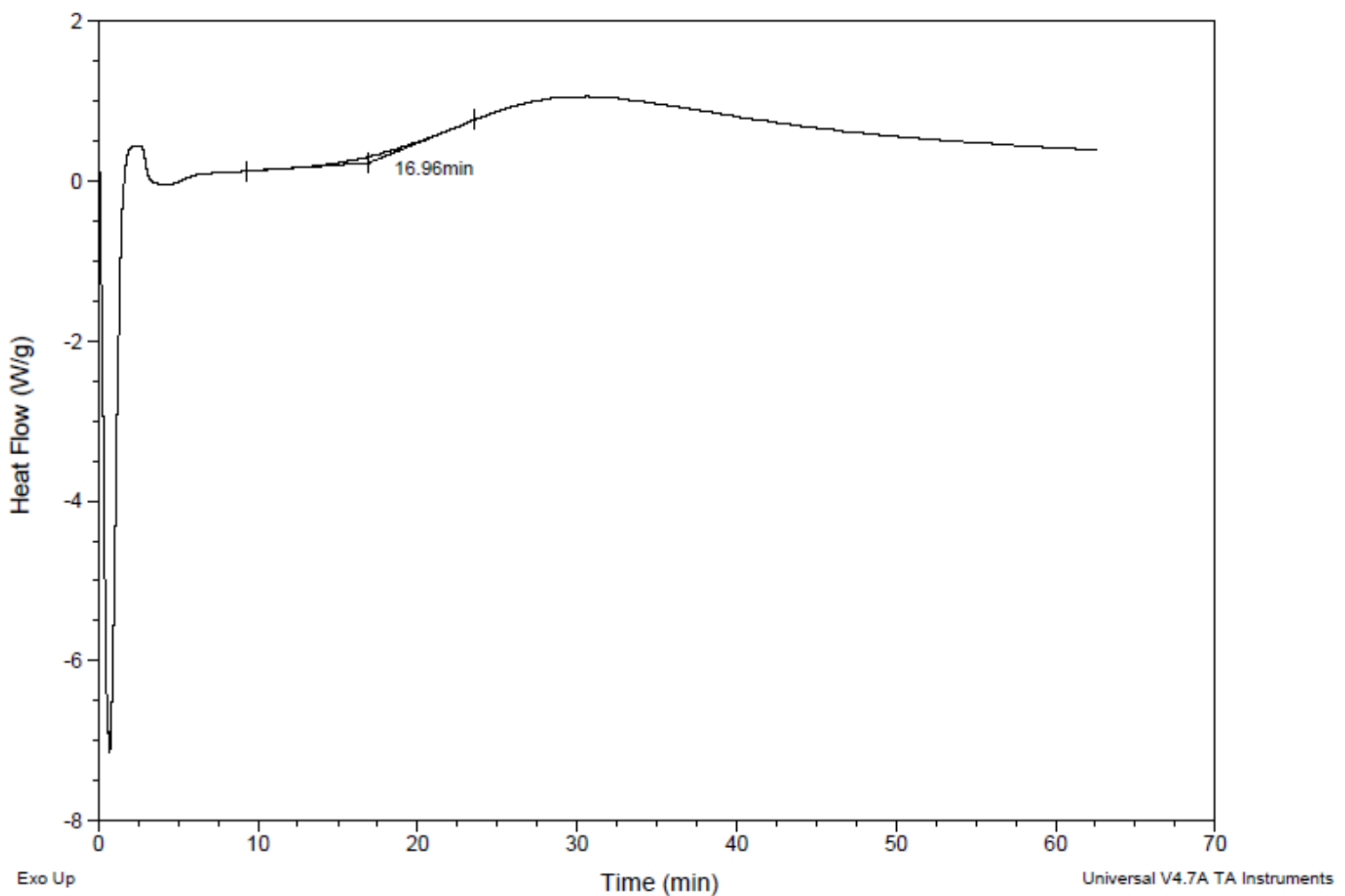

Figura 6. Curva PDSC isotérmica do B100.

Na figura 7 está apresentada a curva não-isotérmica do PDSC com uma rampa de aquecimento de $10^{\circ} \mathrm{C} / \mathrm{min}$. Um pico mais fino e com um aumento drástico do fluxo de calor é característico desse método [10].

O valor de OT é obtido da mesma forma que na curva isotérmica, representando a temperatura máxima que a amostra é resistente à oxidação nas condições específicas do teste. Existem, ainda, os valores de temperatura inicial de oxidação, quando começa a ocorrer o aumento do fluxo de calor, e a temperatura máxima de pico, que representa a temperatura na qual se alcança o valor máximo de fluxo de calor. 


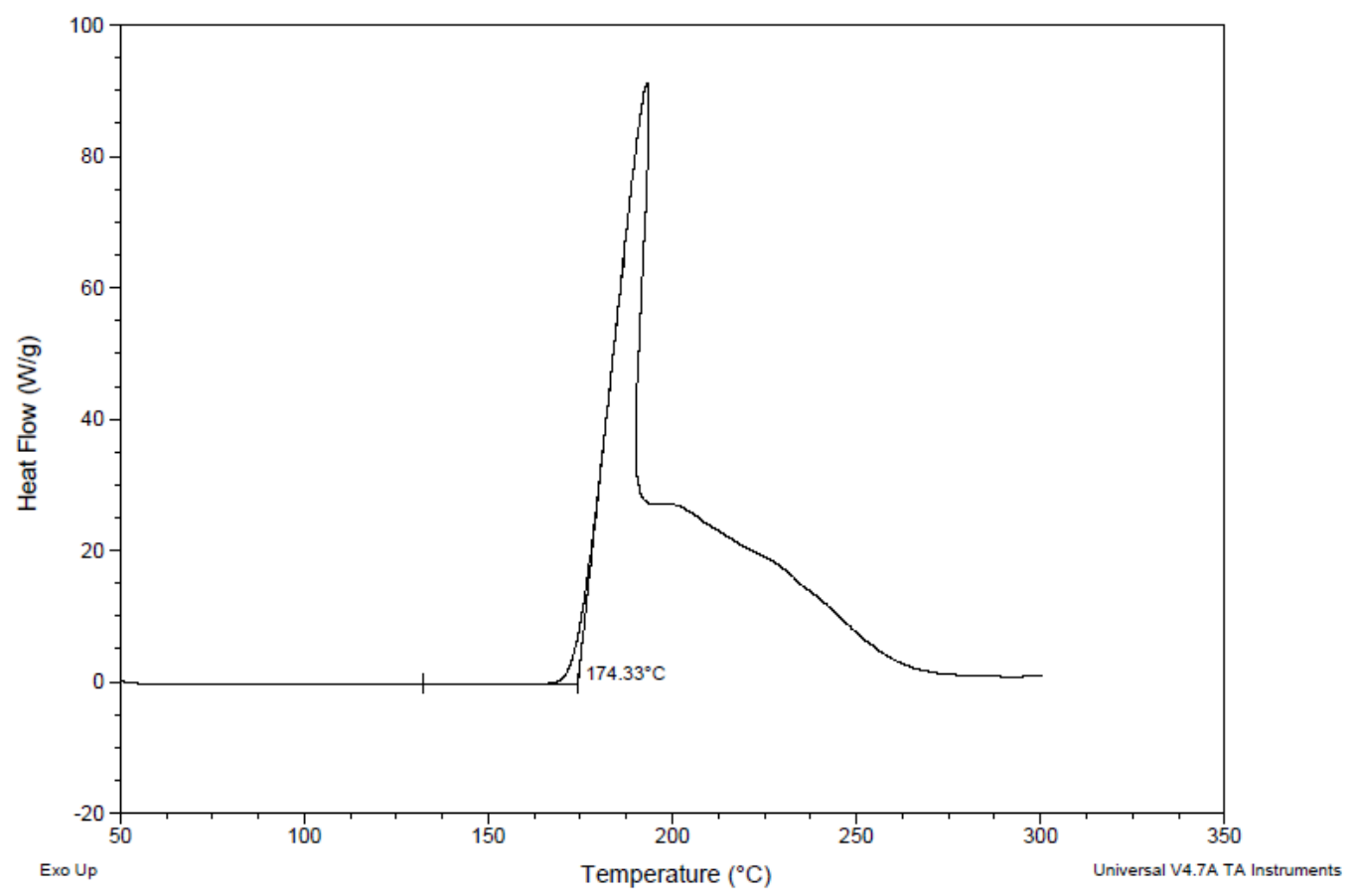

Figura 7. Curva PDSC não-isotérmica do B100.

Na figura 8 está apresentada a curva de condutividade elétrica versus tempo obtida no Rancimat a uma temperatura de $110^{\circ} \mathrm{C}$. O valor de OSI é determinado após a condutividade da água aumentar vertiginosamente, devido a liberação de produtos do processo de oxidação.

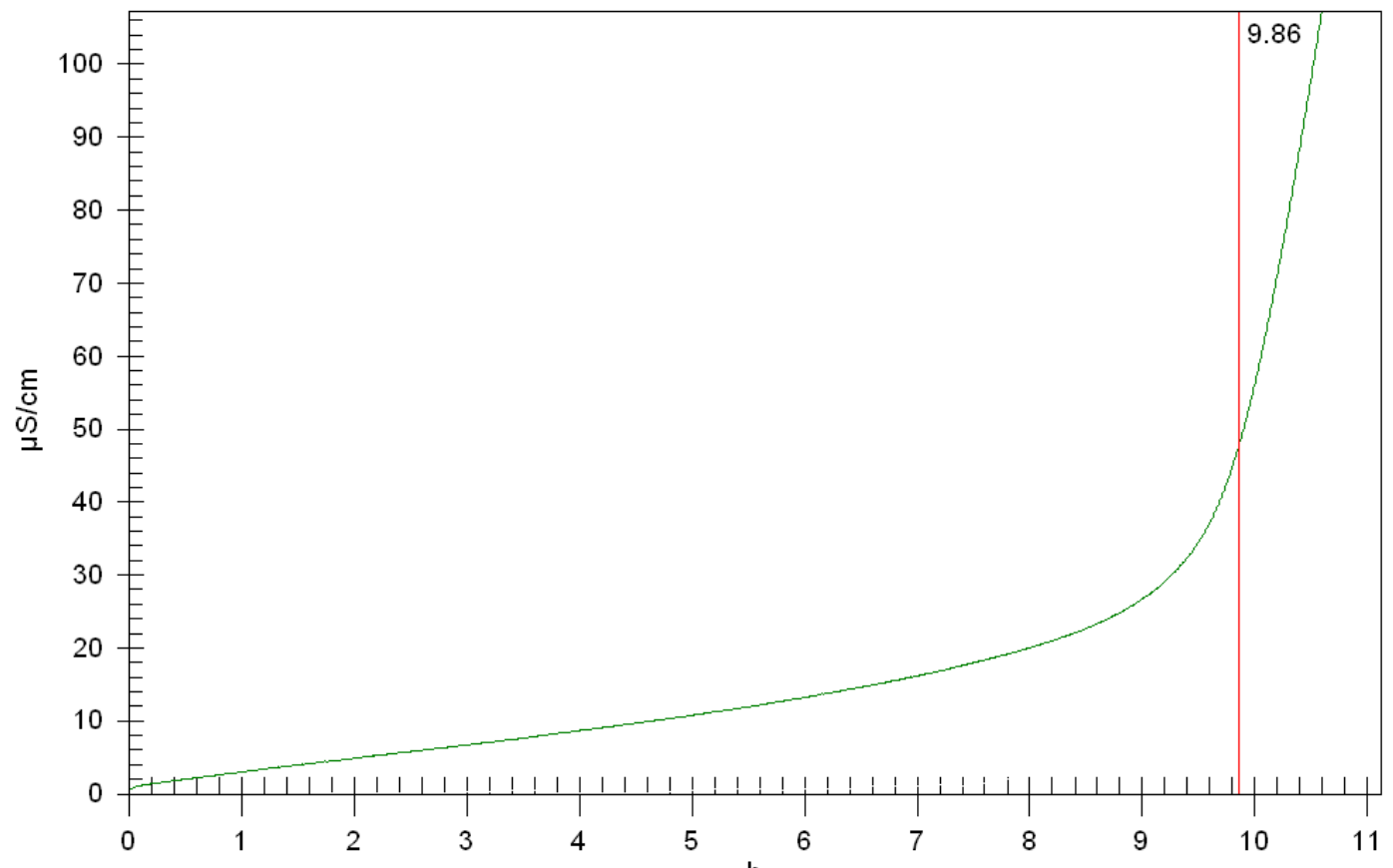

Figura 8. Curva de condutividade elétrica vs tempo do B100.

Apesar da ausência de antioxidantes, o valor obtido para o B100 através do Rancimat foi maior que o limite mínimo de 6 horas determinado pela ANP [6]. Isso é justificado pela alta porcentagem de gordura bovina (sebo) utilizada para a produção desse biodiesel, uma vez que em sua produção foram 
utilizadas como matérias-primas soja (63\%) e sebo (37\%). Usualmente, é utilizado uma quantidade menor de sebo, cerca de $20 \%$.

O sebo tem sua composição formada por ácidos graxos saturados $(48,2 \%)$, monoinsaturados $(49,9 \%)$ e poli-insaturados (1,9\%) [11]. Logo, sua baixa taxa de ácidos graxos poliinsaturados irá conferir ao biodiesel uma alta estabilidade oxidativa. Sendo assim, ao se utilizar um alto teor de sebo como matériaprima, evita-se o uso de antioxidantes ou, pelo menos, diminui a quantidade necessária, reduzindo o custo do processo. Entretanto, essa relação soja/sebo deve ser estudada para que não comprometa as propriedades de fluxo a frio do biodiesel. O biodiesel utilizado, por exemplo, de acordo com a tabela 1 , teve um resultado de $7^{\circ} \mathrm{C}$ na análise de CFPP, o que o torna nãoconforme para comercialização na região Sul do Brasil, nos meses de abril a setembro, conforme é mostrado na tabela 2.

\subsection{Misturas BX}

Na figura 9 é mostrada as curvas não-isotérmicas das amostras B0, B7, B20 (diesel S10) e B100 sobrepostas.

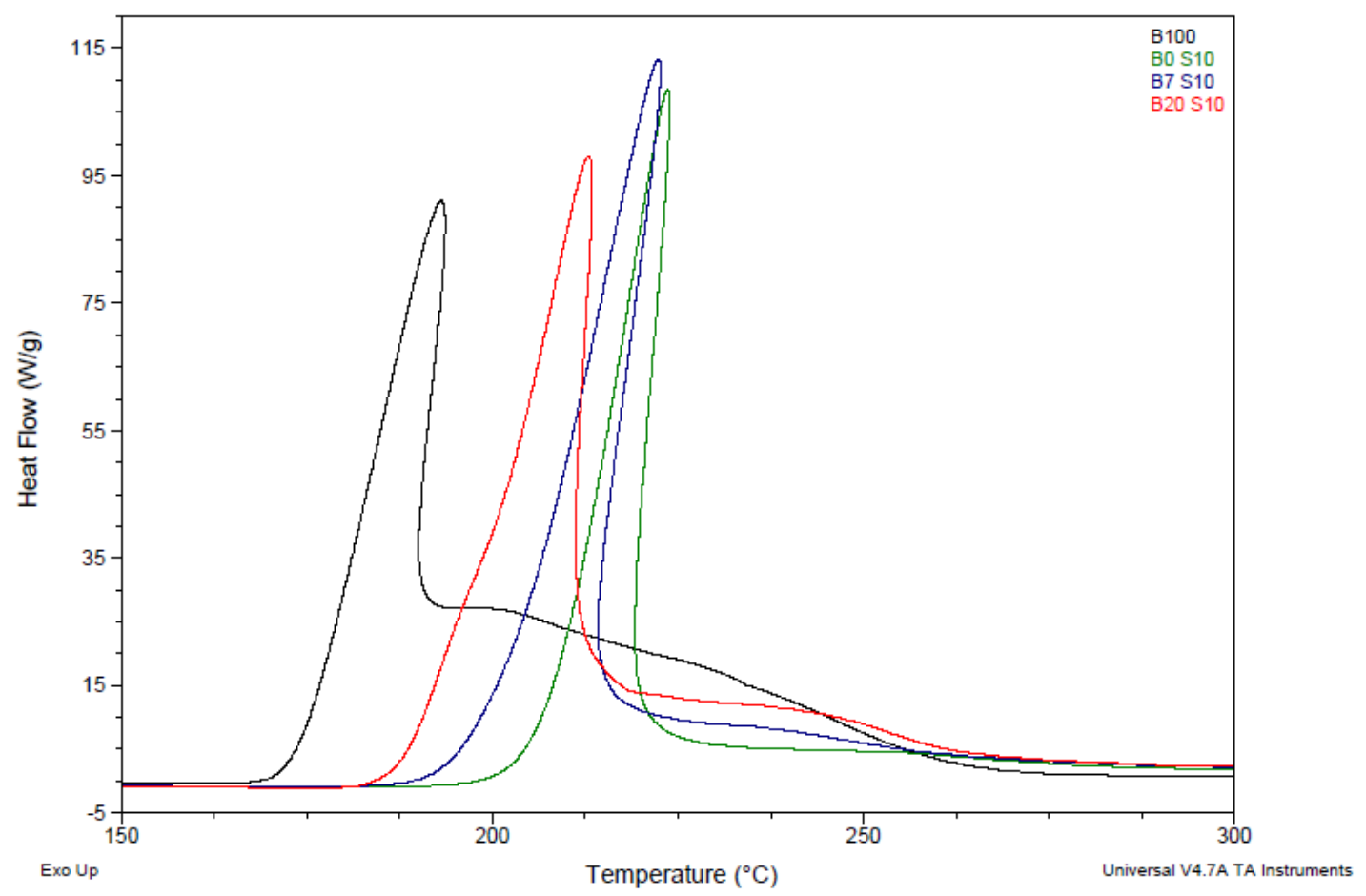

Figura 9. Curvas PDSC não-isotérmicas do B0, B7, B20 (S10) e B100.

Como era esperado, à medida que aumentou-se o teor de biodiesel no diesel a oxidação ocorreu em menores temperaturas, comprovando a menor estabilidade oxidativa do biodiesel. Esse resultado é coerente com outros trabalhos que avaliaram a estabilidade oxidativa do biodiesel e suas misturas com o diesel através do PDSC [12,13]. 
Da mesma forma, pode-se observar pelo Rancimat essa diminuição na estabilidade oxidativa (figuras 10 e 11), uma vez que o valor de OSI encontrado para o B7 foi maior do que o do B20.

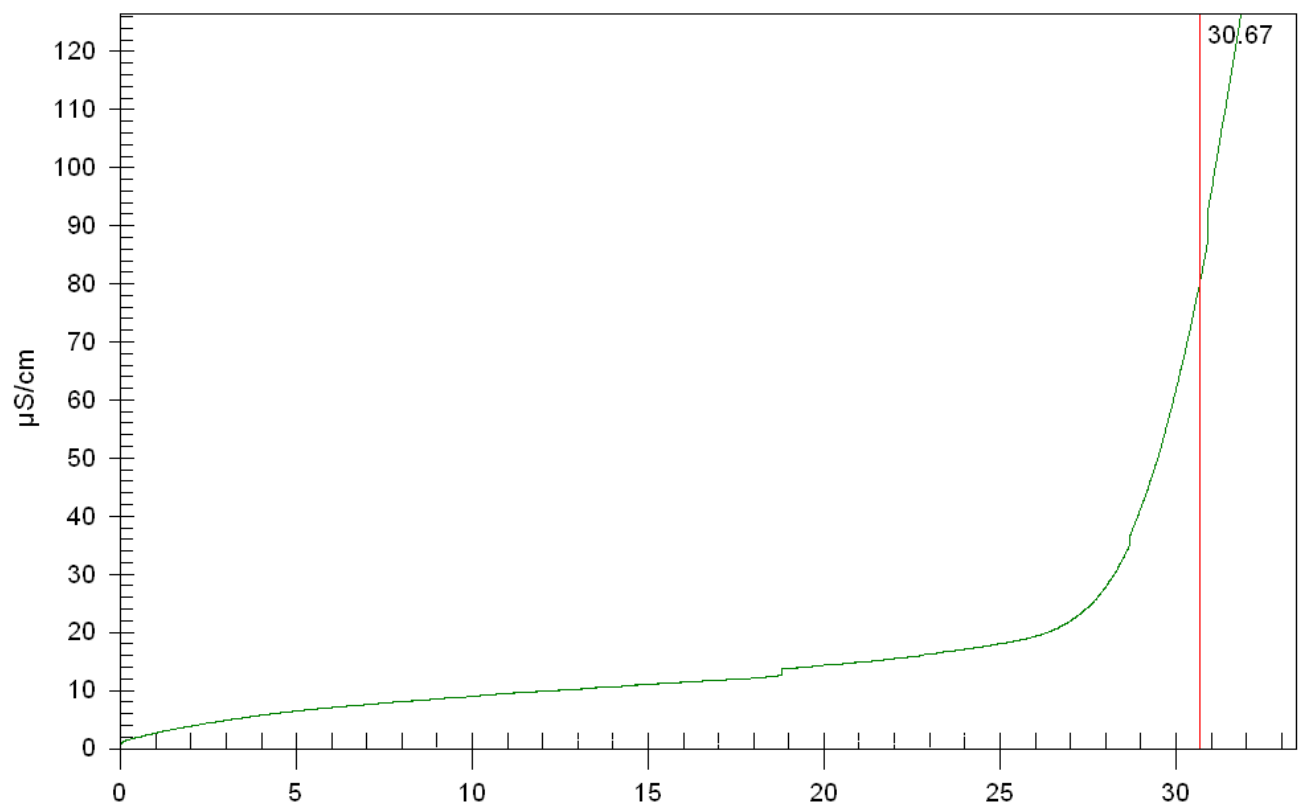

Figura 10. Curva de condutividade elétrica vs tempo do B7 (S10).

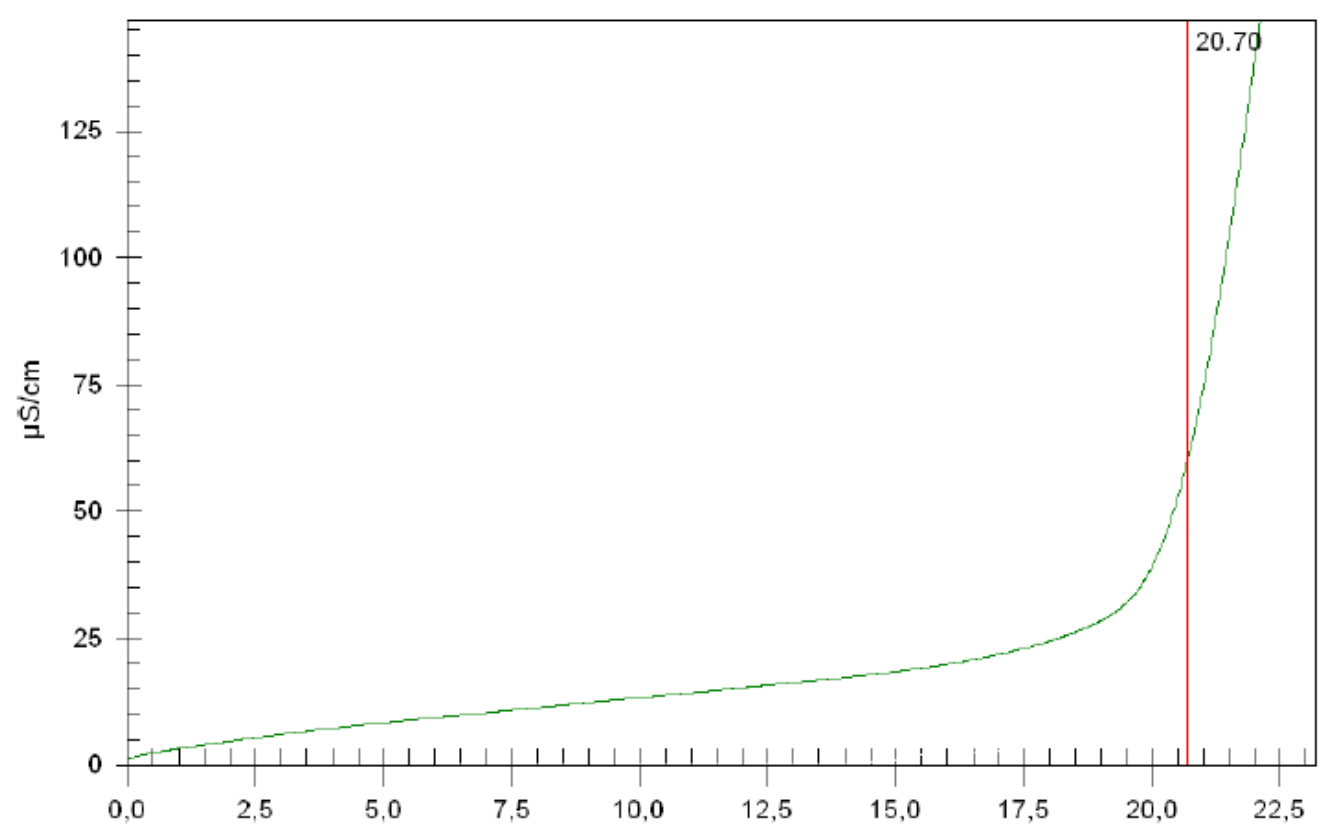

Figura 11. Curva de condutividade elétrica vs tempo do B20 (S10).

Da mesma forma ocorreu com as amostras com diesel S500. Como é possível ver na figura 12, as curvas não-isotérmicas seguiram o mesmo padrão que as curvas das amostras com diesel S10. 


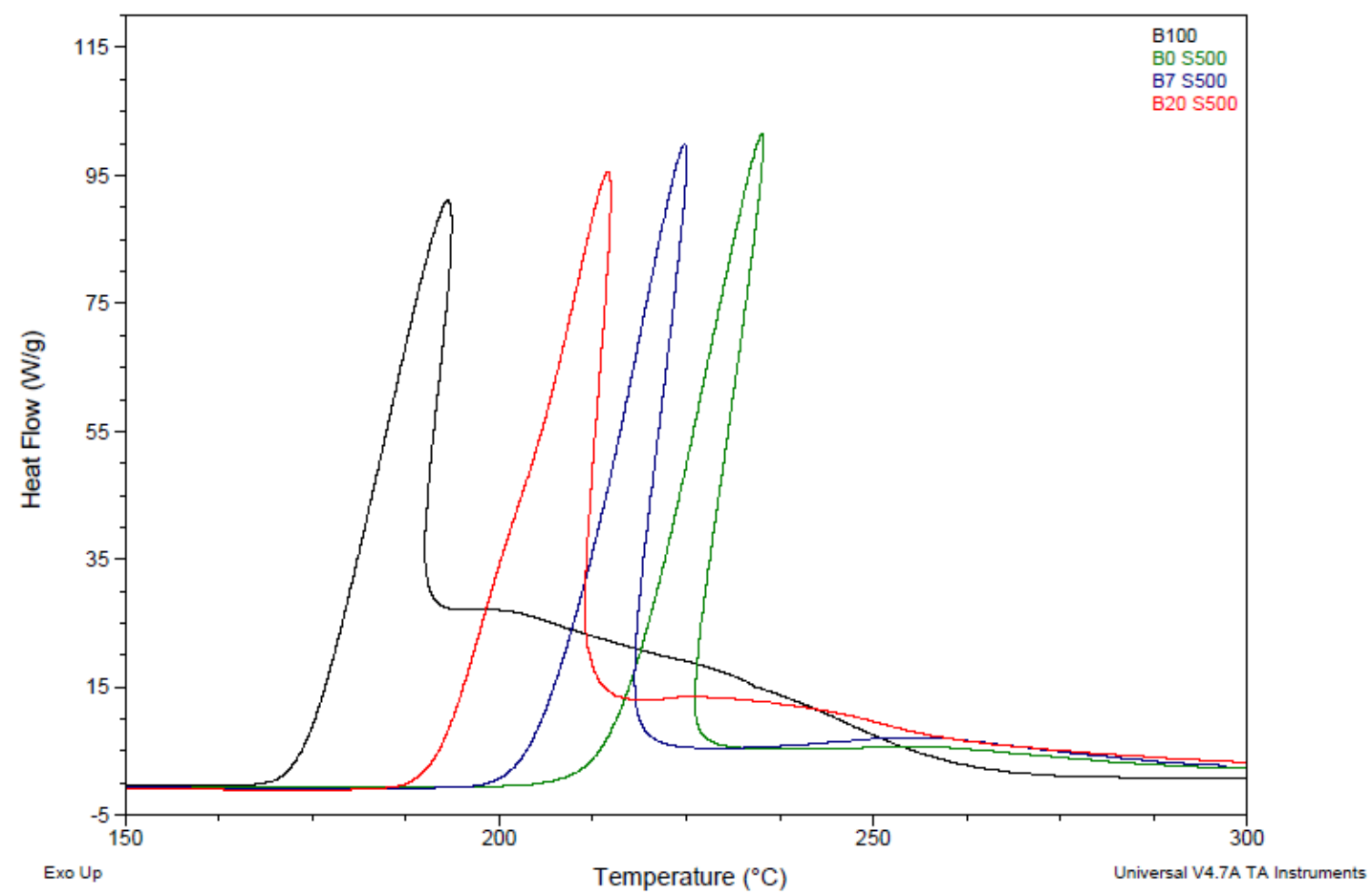

Figura 12. Curvas PDSC não-isotérmicas do B0, B7, B20 (S500) e B100.

$\mathrm{Na}$ figura 13 é feita uma comparação entre as curvas de PDSC de amostras de óleo diesel S10 e S500. Verificou-se que as amostras com diesel S500 são mais estáveis à oxidação. Isso se deve ao fato do enxofre agir como um antioxidante natural para o diesel. Portanto, quanto mais processos de refino forem realizados para gerar um diesel com menor quantidade de enxofre, mais suscetível à oxidação ele será [14]. Karavalakis et al [15] compararam a estabilidade oxidativa de misturas em diversas proporções de biodiesel de diferentes origens com diesel S10 e S50 através do Rancimat e verificaram que o diesel com maior teor de enxofre fornecia à mistura final maiores valores de OSI.

A ANP vem buscando se igualar aos padrões internacionais reduzindo a quantidade de enxofre no diesel, tendo como objetivo reduzir as emissões de SOx. Esse processo começou com a introdução do diesel S50 em 2009, para posterior mudança em 2013 para o diesel S10, e com a descontinuidade do diesel S1800. Portanto, deve-se garantir ainda mais a estabilidade oxidativa do biodiesel, uma vez que a tendência é que seja utilizado óleo diesel com menor quantidade de enxofre, e, por conseguinte, que possua uma menor estabilidade oxidativa [16]. 


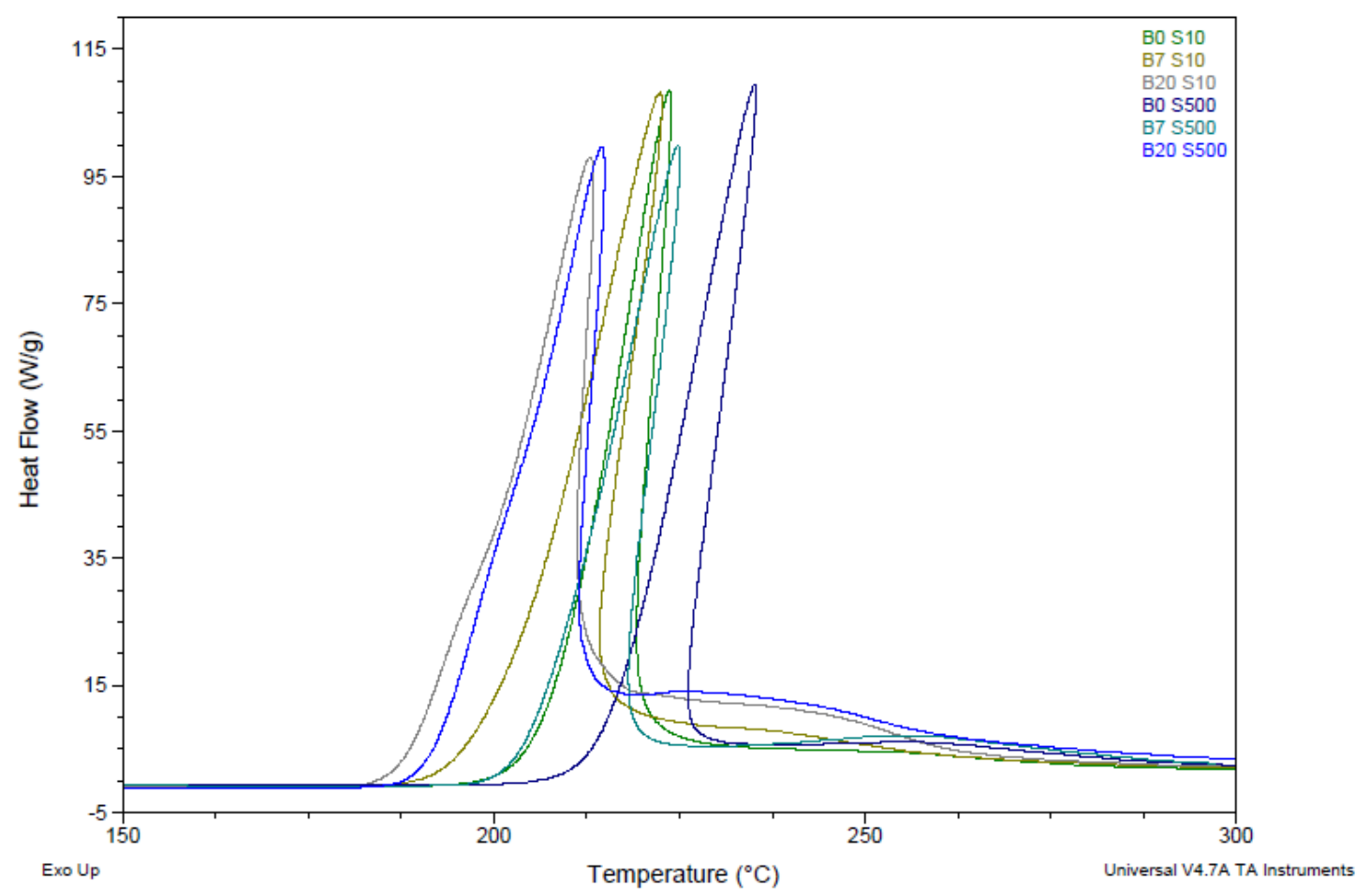

Figura 13. Curvas PDSC não-isotérmicas do B0, B7 e B20 (diesel S10 e S500).

De acordo com a tabela 5, verifica-se que os valores obtidos do Rancimat são coerentes com essa observação, principalmente na mistura com maior teor de diesel, o B7, onde essa discrepância fica ainda mais clara. Com o óleo diesel S10 obteve-se um valor de OSI de 31,03h, já para o S500 foi de 46,08h.

Observa-se que o método do Rancimat para o B100 apresentou valores bastante coerentes entre si. Entretanto, isso não ocorreu para o método das misturas BX, uma vez que os valores obtidos da análise em triplicata apresentaram uma variação significativa. Isso se dá, principalmente, pelos altos valores alcançados. No caso do B7 S500, por exemplo, foram obtidos valores de OSI acima de 40h, o que aumenta consideravelmente o erro da análise. Além disso, conforme aumenta-se o teor de diesel na amostra, a análise se torna menos precisa, uma vez que o diesel acaba evaporando, devido a sua alta volatilidade. Por esse motivo, o método do Rancimat enfrenta algumas resistências para seu uso na avaliação da estabilidade oxidativa de misturas BX, apesar de ser um método bem consolidado para o biodiesel puro. 
Tabela 5. Resultados obtidos no PDSC e no Rancimat

\begin{tabular}{|c|c|c|c|c|c|c|c|}
\hline \multicolumn{8}{|c|}{ PDSC (ํㅡ) } \\
\hline & & 1 & 2 & 3 & Média & Variância & Desvio padrão \\
\hline & B100 & 174,32 & 174,95 & 174,49 & 174,59 & 0,10623 & 0,32593 \\
\hline \multirow{3}{*}{$\mathrm{S} 10$} & B20 & 193,84 & 194,82 & 193,11 & 193,92 & 0,73623 & 0,85804 \\
\hline & B7 & 201,79 & 200,13 & 201,00 & 200,97 & 0,68943 & 0,83032 \\
\hline & B0 & 207,89 & 208,08 & 206,52 & 207,50 & 0,72443 & 0,85114 \\
\hline \multirow{3}{*}{ S500 } & B20 & 195,08 & 194,49 & 195,18 & 194,92 & 0,13903 & 0,37287 \\
\hline & B7 & 206,52 & 207,24 & 205,27 & 206,34 & 0,99363 & 0,99681 \\
\hline & B0 & 215,94 & 215,11 & 215,96 & 215,67 & 0,23530 & 0,48508 \\
\hline \multicolumn{8}{|c|}{ Rancimat (h) } \\
\hline & B100 & 9,97 & 9,80 & 9,86 & 9,88 & 0,00743 & 0,0862 \\
\hline \multirow{2}{*}{$\mathrm{S} 10$} & B20 & 17,75 & 20,70 & 20,60 & 19,68 & 2,806 & 1,675 \\
\hline & B7 & 30,67 & 29,79 & 32,62 & 31,03 & 2,098 & 1,448 \\
\hline \multirow{2}{*}{ S500 } & B20 & 21,03 & 20,82 & 21,21 & 21,02 & 0,03810 & 0,1952 \\
\hline & B7 & 44,60 & 45,50 & 46,44 & 45,51 & 0,847 & 0,920 \\
\hline
\end{tabular}

\subsection{Comparação PDSC/Rancimat}

Observa-se nos valores apresentados na tabela 5 que de modo geral foram obtidos valores mais reprodutíveis através do PDSC do que no Rancimat, principalmente para as misturas com alto teor de diesel, o que confere ao PDSC uma maior precisão na análise da estabilidade oxidativa para biodiesel puro e suas misturas com o diesel.

No PDSC o maior valor de OT encontrado, isto é, do B0 S500 foi $23,53 \%$ maior que o menor valor (B100). Já para o Rancimat, o maior valor de OSI (B7 S500) foi 360,63\% maior que o valor do B100. Essa menor diferença entre valores observada no PDSC é justificada pela utilização de uma rampa de aquecimento. $\mathrm{O}$ mesmo não acontece com o Rancimat, uma vez que ele utiliza uma temperatura fixa. Isso faz com que seja possível utilizar no PDSC uma mesma metodologia tanto para o B100 quanto para as misturas BX sem necessitar de uma análise muito demorada.

Em uma comparação mais precisa, tem-se o valor obtido através de uma isoterma no PDSC e o da curva do Rancimat, ambos na mesma unidade, para a amostra de B100. Enquanto o primeiro valor foi de 16,96 min (figura 6), o segundo foi de 593 min $(9,88 \mathrm{~h})$ (tabela 5$)$, um valor aproximadamente 35 vezes maior, o que comprova que o PDSC é capaz de fornecer uma resposta 
bem mais rápida. Isso irá gerar um custo menor para a análise, aumentando, assim, a sua eficiência. Esse fato ocorre, principalmente, pelo uso da pressão, que irá acelerar ainda mais o processo de oxidação. Sendo assim, tem-se uma variável a mais que poderá ser utilizada para se otimizar uma determinada metodologia.

$\mathrm{Na}$ figura 14 é mostrado como os valores de OT e OSI se comportaram a medida que o teor de biodiesel no diesel aumenta. A diferença entre os valores das amostras com óleo diesel S10 e S500 diminuíram a medida que o teor de biodiesel aumentava. Para o B7, por exemplo, essa diferença foi de 14,48h para o Rancimat e $5,37^{\circ} \mathrm{C}$ para o PDSC, enquanto que para o B20 essa diferença foi de $1,34 \mathrm{~h}$ para o Rancimat e $1,00^{\circ} \mathrm{C}$ para o PDSC. Além disso, é possível observar que os valores de OT e OSI diminuíram a medida que o teor de biodiesel aumentou.

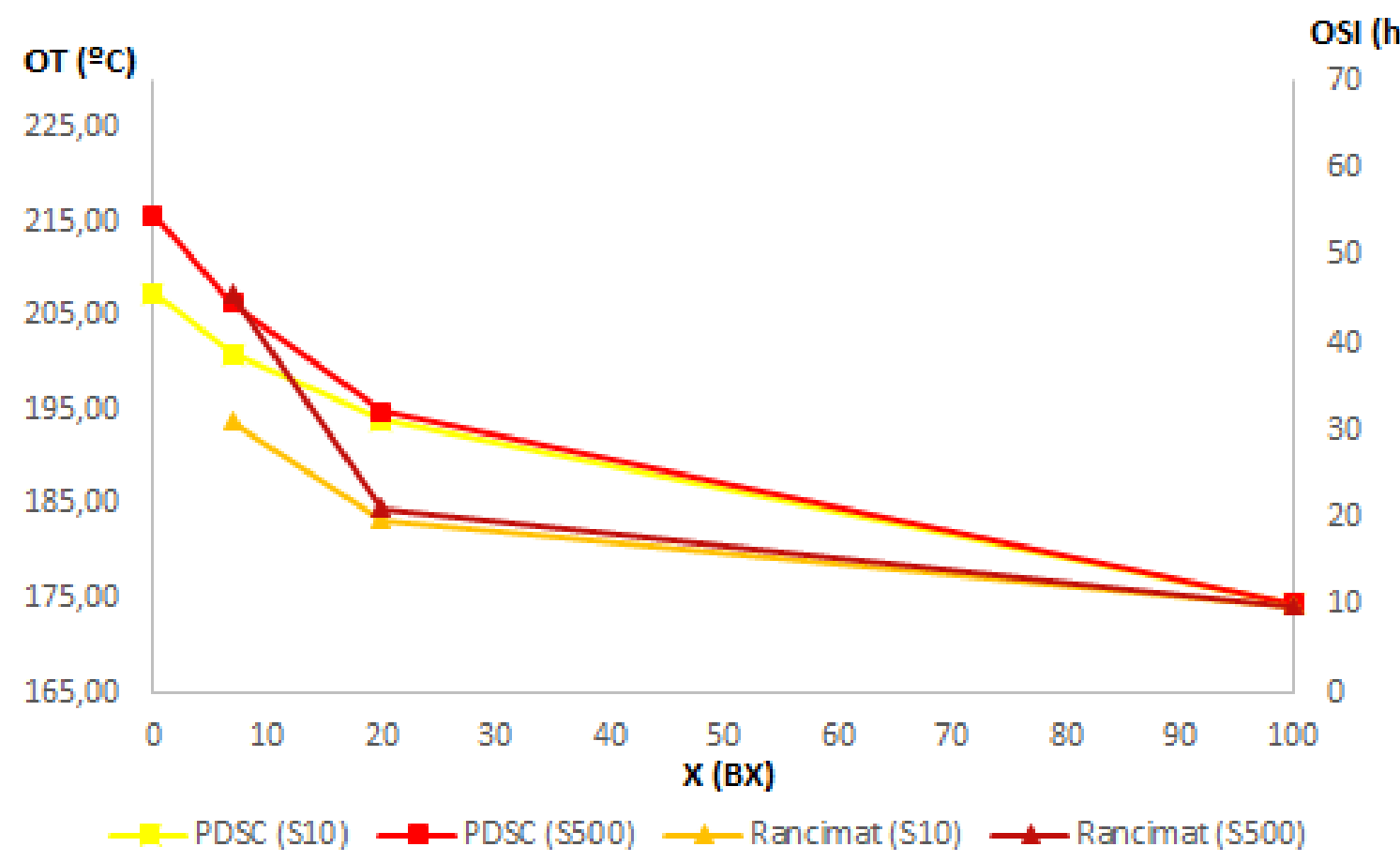

Figura 14. Valores de OT e OSI em função do teor de biodiesel no diesel (onde X representa o teor de biodiesel na mistura BX).

\section{CONCLUSÃO}

Ao analisar as amostras de B0, B7, B20 e B100 através do PDSC verificou-se que foram obtidos resultados coerentes, tanto entre si, quanto em relação a um método já estabelecido, o Rancimat. Logo, pode-se dizer que o PDSC se mostrou uma técnica robusta na avaliação da estabilidade oxidativa de biodiesel e suas misturas com diesel.

Por conta disso, o PDSC se mostrou como uma possível alternativa ao Rancimat, método atualmente reconhecido pela ANP para a determinação da estabilidade oxidativa de biodiesel, uma vez que possui diversas vantagens, tais como: menor tempo de análise, menor quantidade de amostra, aplicável ao biodiesel puro e suas 
misturas com o diesel, além do uso da pressão que faz com que se tenha um método de oxidação acelerada mais eficiente.

Como era esperado, comprovou-se através do PDSC e do Rancimat que a medida que se aumentou o teor de biodiesel, a mistura passou a ter uma estabilidade oxidativa menor, uma vez que se obteve menores valores de OT e OSI. Além disso, verificouse que a concentração de enxofre no diesel também é um aspecto importante. Foi verificado que amostras com óleos diesel S500 são mais estáveis à oxidação do que as com $\mathrm{S} 10$, já que o enxofre age como um antioxidante natural.

\section{REFERÊNCIAS}

[1] RESOLUÇÃO CNPE no 11, de 14/12/2016. Disponível em http://www.mme.gov.br. Acesso em 22/05/2017.

[2] RESOLUÇÃO ANP no 45 de 25/08/2014. Disponível em http://www.anp.gov.br. Acesso em: 18/05/2017.

[3] RESOLUÇÃO ANP no 30 de 23/06/2016. Disponível em http://www.anp.gov.br. Acesso em: 18/05/2017.

[4] DUNN, R. O. Oxidative stability of biodiesel by dynamic mode PressurizedDifferential Scanning Calorimetry (P-DSC). American Society of Agricultural and Biological Engineers. v. 49, n. 5, p. 1633-1641, 2006

[5] RAMALHO, E. F. S. M.; ALBUQUERQUE, A. R.; SOUZA, A. L.; BARRO, A. K.; MAIA, A. S. Use of different techniques in the evaluation of the oxidative stability of poultry fat biodiesel. Journal of Thermal Analysis and Calorimetry. v. 106, p. 787791, 2011.

[6] RESOLUÇÃO ANP no 14 de 11/05/2012. Disponível em http://www.anp.gov.br. Acesso em: 18/05/2017.

[7] RESOLUÇÃO ANP no 50 de 23/12/2013. Disponível em http://www.anp.gov.br. Acesso em: 18/05/2017.

[8] EN 14112 - Fat and oil derivatives - fatty acid methyl esters (FAME) Determination of oxidation stability (accelerated oxidation test)

[9] EN 15751 - Automotive Fuels, Fatty Acid Methyl Ester (FAME) Fuel and blends with Diesel Fuel - Determination of Oxidation Stability by Accelerated Oxidation Method.

[10] SANTOS, N. A. Propriedades Termo-Oxidativas e de Fluxo do Biodiesel de Babaçu (Orbignya phalerata). Dissertação de mestrado. Universidade Federal da Paraíba. Paraíba, 2008.

[11] LORA, E. E. S.; VENTURINI, O. J. Biocombustíveis. 1를 ed. Rio de Janeiro: Interciência, 2012.

[12] SHAH, S. N.; SHARMA, B. K.; MOSER, B. R.; ERHAM, S. Z. Preparation and Evaluation of jojoba oil methyl esters as biodiesel and as a blend component in ultralow sulfur diesel fuel. Bioenergy Research. v. 3, p. 214-223, 2010.

[13] SHERMA, B. K.; SUAREZ, P. A. Z.; PEREZ, J. M.; ERHAN, S. Z. Oxidation and low temperature properties of biofuels obtained from pyrolysis and alcoholyses of soybean oil and their blends with petroleum diesel. Fuel Processing Technology. v. 90, p. 1265-1271, 2009.

[14] LEWIS, R. E. Safety and integrity of marine fuel pumps operating on $0.1 \%$ sulfur marine gas oil. Power Research Inc. 2009. 
[15] KARAVALAKIS, G.; STOURNAS, S.; KARONIS, D. Evaluation of the oxidation stability of diesel/biodiesel blends. Fuel. v. 89, p. 2483-2489, 2010.

[16] RESOLUÇÃO ANP no 46 de 20/12/2012. Disponível em http://www.anp.gov.br. Acesso em: 20/05/2017. 